\title{
Self-esteem and Academic Success as Influenced by Reading Strategies
}

\author{
Eghbal Zarei \\ $\mathrm{PhD}$, Hormozgan University, Bandar Abaas, Iran
}

Nasrin Shokrpour (Corresponding author)

PhD, English Dept., Faculty of Paramedical Sciences, Shiraz University of Medical Sciences, Shiraz, Iran

Tel: 98-711-843-1031Ｅ-mail: shokrpourn@gmail.com

Elham Nasiri

MA, Shiraz University of Medical Sciences, International Branch, Shiraz, Iran

Reza Kafipour

Dept. of Foreign Languages, Shiraz Branch, Islamic Azad University, Shiraz, Iran

Received: September 7, 2011

Accepted: October 24, 2011

Published: February 1, 2012

doi:10.5539/elt.v5n2p17

URL: http://dx.doi.org/10.5539/elt.v5n2p17

\begin{abstract}
This study aimed at determining the effect of instruction in cognitive and metacognitive strategies on the students' educational self-esteem and academic performance. 87 students were selected through random sampling. The two first groups were consciously taught about cognitive and metacognitive strategies. All the classes were taught by the same teacher. Pourmoghaddasian's self-esteem questionnaire (1994) was used to collect the data. The results indicated that there were significant differences between the pre- and post-test mean scores of the students' self-esteem, their scores in the course, and their academic success in all the three groups. The results of one-way ANOVA revealed that there was no significant difference between the self-esteem measures of those students who were taught congnitive and metacognitive strategies as compared to those taught traditionally. However, there were significant differences between their total scores in the course and their academic success measures.
\end{abstract}

Keywords: Cognitive, Metaconitive, Reading strategies, Educational self-esteem

\section{Introduction}

Although attention has been paid to research in the area of metacognition for more than three decades, the term "metacognition" used by researchers or instructors is still a vague one and sometimes confusing. After a decade of discussion on this issue, Flavel (1981) acknowledged that we have not yet reached a clear understanding of metacognition.

Strategies are referred to as learning techniques, behaviors, or learning-to-learn, problem solving, or study skills. To Richards, Platt and Platt (1992), strategies are those procedures used in learning, thinking, etc. which serve as a way of reaching a goal. Learning strategies are those operations or techniques undertaken either consciously or often unconsciously by individuals to improve, enhance, or facilitate the comprehension, storage, retrieval, recall, and use of information (Oxford \& Crookal, 1989; Oxford \& Niokos, 1989; Ehrman \& Oxford, 1990). The present study focuses on two main strategies, cognitive and metacognitive.

Prokop (1989) defines cognitive strategies as related to the "task at hand and the manner in which linguistic information is processed" (p.17). This category includes the following strategies:

1- Rehearsing: repeating the names of items or objects to be remembered.

2- Organizing: grouping and classifying words, terminology, or concepts according to their semantic or syntactic attributes.

3- Inferring: using the information in the text to guess the meaning of new linguistic items, predicting outcomes or completing missing parts. 
4- Summarizing: intermittently synthesizing what one has read to ensure that information has been retained.

5- Deducing: applying rules to the understanding of language.

6- Imaging: using visual images (either general or actual) to understand and remember new verbal information.

7- Transferring or inducing: using known linguistic information to facilitate a new learning task.

8- Elaborating: linking ideas contained in new information, or integrating new ideas with old information.

On the other hand, in Phakiti's research (2003), it is pointed out that the basic concept of metacognition is the notion of thinking about thinking. This thinking can be about what the person is currently doing. As he notes, metacognition is deliberate, planned, intentional, goal directed, and future oriented mental processing that can be used to accomplish cognitive tasks (Flavel, 1981).

According to Shokrpour \& Fotovatian (2006) and Marzban (2006) and based on O'Malley \& Chamot's framework (1990), metacognitive strategies are higher order executive skills that may entail planning for, monitoring, or evaluating the success of a learning activity. Similar definitions have been given by Salataci, \& Akyel (2002), Yin \& Agnes (2001), stating that metacognitive strategies consist of:

1- Selective or directed attention: focusing on special aspects of learning task, planning to find key words or phrases.

2- Planning: arranging in advance for the organization of either written or spoken discourse.

3- Monitoring: reviewing and attention to a task, comprehension of information that should be remembered, or production while it is occurring.

4- Evaluating: checking comprehension after completion of a receptive language activity, or evaluating language production after it has taken place.

Many researchers believe that using metacognitive strategies is essential to make learning meaningful, as stated by Nolan \& Morgan (2000). In general, metacognitive strategies dominate the learner's ability in being conscious and controlling his/her approach (Nolan \& Morgan, 2000). Research shows that developing metacognition in science classes encourages the students to modify their thoughts about scientific concepts and successfully solve their problems (Ricky \& Stacy, 2000). Learners employ these strategies only when their details have been made clear and knowledge about how and when to use them have been specified and the students feel ready to take use of theses strategies (Brown \& Day, 1983). Skills and techniques of learning how to learn includes feelings or behaviors that facilitate studying, understanding, learning how to learn, and knowing basic knowledge of the person. This is crucial for the learners who are on the brink of failure or weakness in their study (Ricky \& Stacy, 2000). The reason strategies are instructed to the students is to make them succeed in becoming skillful strategic learners (Lefrancois, 1994). In spite of this fact, Borkowski and Muthagrishna (1992) believe that teachers lack practical samples of metacognition to control their teaching. To them, what is needed for such samples is to prepare structural frameworks to teach basic strategies.

Students can be independent learners only when they know and understand what they are expected to do in the process of learning and how they must learn. The term to be used to show such knowledge is awareness and control beyond learning metacognition. Because instructions to teach metacognition differ deeply from teaching traditional sciences, the Project of Enhancing Effective Learning (PEEL) has greatly helped teachers and students to adjust to and develop strategies of effective science teaching (Scott, 2000). The project focused on involving students more in their own learning. It consists of 180 teaching procedures focusing on teaching strategies. Motevalli (1997) approved the effect of teaching metacognitive reading strategies on reading comprehension, and learning speed of the high school freshmen. The most important approach being used in this study to teach metacognitive strategies while having the most impact on improving reading comprehension of the students was interactive teaching.

Ababaf (1996) revealed that academically successful learners take the most advantage of cognitive and metacognitive strategies. In another study, Avansian (1998) investigated the effect of teaching metacognitive instruction on the students of bilingual schools in Tehran, Iran. The results showed that instruction on metacognitive strategies enhances both reading comprehension and learning speed of the students.

Many researchers believe that using cognitive and metacognitive strategies will, doubtlessly, lead to meaningful learning, persuading the students to study with a much deeper understanding, more vision and interest, greater confidence, faster learning, and lower stress (Carr \& Jessup, 1997). Generally, metacognitive skills and related techniques control the learners' ability in their awareness and conscious control on their thoughts as human beings (Nolan \& Morgan, 2000). In the last few years, the educational systems in developed countries have been based on cognitive and metacognitive strategies and traditional methods like lectures, conferences, etc. have been left aside (Nolan \& Morgan, 2000). These strategies as well as other terms used in this study are defined as follows: 


\section{Metacognitive Strategies:}

These strategies are the techniques to control and monitor cognitive strategies such as setting goals for learning, questioning, and evaluating and include monitoring, organizing, and planning.

Cognitive strategies:

Cognitive strategies are the techniques that help the learner store, combine and recall the required information.

Educational self esteem:

It is what the students believe about learning, school, teachers, self when comparing their own learning to that of other students. In this study, it is the score that the students gain from educational self esteem index of Pourmoghaddasian (1994).

Educational performance:

It is the rate of hard working or activity of the student(s) in the class during the course. In this research, it is the students ' GPA and mean scores of the science at the end of the course.

Considering the monitoring power of metacognition as an important factor in cognition and learning how to learn by the students, this study aimed at investigating whether education based on cognitive and metacognitive strategies, compared with usual methods of teaching at schools, has any effect on the students' self esteem, their performance in science course, and total educational performance.

\section{Research Questions and Hypotheses}

1- Is there a significant difference between the mean scores of educational self esteem and educational performance in the pre- and post tests in the cognitive group?

2- Is there a significant difference between the mean scores of educational self esteem and educational performance in the pre- and post tests in the metacognitive group?

3- In comparison with other groups, is there a significant difference between the students' pre- and post tests scores in the course of natural sciences in the metacognitive group?

4- In comparison with other ordinary learning methods, do cognitive and metacognitive strategies increase the students' educational self esteem?

5- In comparison with other ordinary learning methods, do cognitive and metacognitive strategies increase the students' educational performance?

Based on the research questions, the following hypotheses were made:

1. There is a significant difference between the mean scores of educational self esteem and educational performance in the pre- and post tests in the cognitive group.

2. There is a significant difference between the mean scores of educational self esteem and educational performance in the pre- and post tests in the metacognitive group.

3. In comparison with other groups, there is a significant difference between the students' pre- and post tests scores in the course of natural sciences in the metacognitive group.

4. In comparison with other ordinary learning methods, cognitive and metacognitive strategies increase the students' educational self esteem.

5. In comparison with other ordinary learning methods, cognitive and metacognitive strategies increase the students' educational performance.

\section{Material and Method}

\subsection{Participants}

This is a cross-sectional, case control study with pre- and post-tests. The participants of the present study included 87 female third grade students of guidance school; they were all 14 years old. They were randomly selected from three classes of a school which was selected randomly among all secondary schools in the third educational district (In Shiraz there are 4 distinct educational districts categorized based on the setting). They were divided into two experimental and one control groups (29 in the cognitive group, 29 in the metacognitive group, and 29 in the control group).

\subsection{Instruments}

The instrument used in the study was a Likert type self esteem questionnaire containing 40 items, each with four 
choices of completely disagree, disagree, agree, and completely agree. The questionnaire was made by Delavar (1993) and has been applied in many studies. The reliability of the questionnaire was measured to be 0.78 (Pourmoghaddasian, 1994). The students' Grade Point Average (GPA) and their scores in the course of natural sciences were also considered as an indication of their academic success.

\subsection{Procedure}

The study was conducted in three phases:

1) Pre-test

2) Instruction through cognitive and meta-cognitive approaches (the experimental interventions)

3) Post-test

The self esteem questionnaire was given to the control and experimental groups, aiming at determining their self esteem level before the study. Then, the students in the two experimental groups underwent 9 sessions of training on cognitive and metacognitive strategies, each lasting an hour (totally 9 hours). In these sessions, the teacher explained and practiced the strategies mentioned in the review of literature section in detail in the classroom. Each class was held twice a week and taught by an experienced teacher for two months. The control group was traditionally taught and received no specific instruction on the use of the above-mentioned strategies. The teacher only worked on reading comprehension, asking the students to read silently and then explained about the vocabularies and the gist of reading passages. The groups were compared through a post-test at the end. The participants gave their informed consent to participate in the study and their parents and school authorities approved the study to be conducted. The students' GPA was also considered and their scores in the natural sciences (out of 20) were considered for the analysis.

\section{Data Analysis}

In order to analyze the data, descriptive statistics, t-test and ANOVA were applied in SPSS software 11.5 and the $\mathrm{p}<$ 0.05 was considered as significant.

\section{Findings}

Descriptive findings including the mean, standard deviation, minimum and maximum scores, the number of participants in the pre- and post-tests and variables including educational self esteem, science scores, and educational performance of the female students are shown in Table1.

[Insert Table 1 here]

Related results as to each hypothesis are presented in Tables 2-10.

Hypothesis 1: There is a significant difference between self esteem and educational performance mean scores in the pre- and post tests in the cognitive group.

To test this hypothesis, t- test of dependant groups was used. The results showed that there was a significant difference between the students' mean scores of educational self esteem in the pre- and post-tests in the cognitive group. Table 2 shows the findings.

[Insert Table 2 here]

Also, to compare the students' educational performance in the pre- and post-tests in the cognitive group, dependant group's t-test was used. The obtained results showed that there was a significant difference between the students' educational performance in pre- and post-tests in the cognitive group. (Table 3)

[Insert Table 3 here]

Hypothesis 2: There is a significant difference between the mean scores of educational self esteem and educational performance in the pre- and post tests in the metacognitive group.

Based on the results, there was a significant difference between the students' pre- and post-test mean scores of self esteem in the metacognitive group. Table 4 shows the results.

[Insert Table 4 here]

Also, to compare the students' educational performance scores in pre- and post-tests in the metacognitive group, the results of the t-test revealed a significant difference between the students' pre- and post-test scores regarding their educational performance in the meta-cognitive group (Table 5).

[Insert Table 5 here]

Hypothesis 3: In comparison with other groups, there is a significant difference between the students' pre- and post 
tests mean scores in the course of natural sciences in the metacognitive group.

Based on the results, there was a significant difference between the pre- and post-test scores in the science course in the metacognitive group. (Table 6)

[Insert Table 6 here]

Hypothesis 4: In comparison with other ordinary learning methods, cognitive and metacognitive strategies increase the students' self esteem.

In order to analyze the data, ANOVA was used. The results revealed that there was a significant difference between the mean score of the students' educational self esteem in the cognitive and metacognitive and the control group. (Table 7)

[Insert Table 7 here]

As revealed in the Table, there is a significant difference between the mean scores of educational self esteem of the students in the cognitive, meta- cognitive, and control groups. To see which groups had these differences, Scheffe test was used. The result of this test revealed that this difference existed between the cognitive and control groups, and metacognitive and control groups.

[Insert Table 8 here]

As indicated in the Table, there is a significant difference between the metacognitive and control group. The cognitive group also significantly differs from the control group. But there is no difference between the cognitive and meta- cognitive groups.

Hypothesis 5: In comparison to traditional methods, cognitive and meta-cognitive approaches increase the students' total educational performance.

The results revealed that there was a significant difference between the students' total educational performance in the cognitive and meta-cognitive groups, and the control ones (Table 9).

[Insert Table 9 here]

As observed in the Table, there was a significant difference between the student's mean scores in total educational performance in the cognitive, meta-cognitive, and control groups. To see which group had these differences, Scheffe test was applied. The obtained results showed that there was a significant difference between the cognitive group and the control one, and also between the meta-cognitive group and the control one (Table 10).

[Insert Table 10 here]

As it can be seen in the Table, there is a significant difference between meta-cognitive and control groups and between cognitive and control groups, in the significance level of $p<0.001$, but there is no difference in the total educational performance between cognitive and meta-cognitive groups.

\section{Discussion and Conclusion}

According to the results of this study, there was a significant difference between pre- and post test scores in the students' self esteem of the cognitive group. The results of this hypothesis are in line with the findings of Weinstine and Hium (1998), Ricky \& Stacy (2000), Nolan \& Morgan (2000), Schommer (1993), Motevalli (1997), and Ebrahimi Ghavamabadi (1998).

To elaborate the findings of this hypothesis, it is understood that cognitive knowledge helps the leaner to become conscious of his learning and his improvement rate. Once one understands that he has noticeably improved his learning and that such improvement is consistent with is/her goals, self esteem towards education is significantly enhanced. This occurs when the student has managed to perform well in his lessons and thereby has begun to use cognitive strategies properly in his learning process. It can be concluded that instructing cognitive strategies to the students leads to their better reading comprehension. As a result, their behavior in learning strategies will improve. The newly gained information will be organized and stored more efficiently, combined with new information, and end in enhanced improvement in the students' understanding. (See Shokrpour et al., 2011)

Also, the results of the t-test for dependent groups revealed that there was a significant difference between the preand post test scores of overall educational performance of the students in the cognitive group. The findings of this hypothesis are consistent with those of Gardner (1990), Brown \&Palinscar (1982), Weinstein \& Hium (1998), Ricky \& Stacy (2000), Anderson (1990), Woolfolk (1995), Hacker (1999), Carr \& Jessup (1997), Scott (2000), Seif (2000), Ebrahim Ghavamabadi(1998), Ababaf (1996), Avansian (1998), and Barkhordarpour \& Sarmad (2000).

These findings reveal that instructing such strategies will lead the learner to learn with a high self esteem. The 
students who benefit from such strategies are hard working, persevering, and responsible students. Therefore, it seems rather sensible that teaching such strategies to the students enhances their overall educational performance.

Furthermore, there was a significant difference between the pre- and post- test scores of self esteem of the students in the metacognitive group.

According to other studies as Weinstein \&Hium (1998), Ricky \& Stacy (2000), Nolan \& Morgan (2000), Schommer (1993), Seif (2000), Motevalli (1997), and Ebrahimi Ghavamabadi (1998), what can be inferred from the findings of this hypothesis is that metacognitively oriented learners learn actively and consciously know when they have better comprehension. One more important benefit is, probably, that they know when they do not comprehend. Such learners deal with their homework and activities with high self esteem and they are sure they can easily handle them. The least profit for them is that they have the sensation that they know how to deal with such activities. This significantly affects their self esteem and changes their approach to education.

Also, there was a significant difference between the pre- and post test scores of overall educational performance of the students in the metacognitive group. The findings of this hypothesis are consistent with those of Brown \& Palinscar (1982), Weistein \& Hium (1998), Ricky \& Stacy (2000), Anderson (1990), Woolfolk (1995), Hacker (1999), Carr \& Jessup (1997), Wolf (1997), Scott (2000), Seif (2000), Ebrahimi Ghavamabadi (1998), Ababaf (1996), Avansian (1998), and Barkhodarpour \& Sarmad (2000) who state that instructing metacognitive strategies positively affects the students' educational performance.

As to the third hypothesis, there was a significant difference between the sciences pre- and post-test scores of the students in the metacognitive group. The findings of this hypothesis are consistent with those of Brown \& Palinscar (1982), Weinstein \& Hium (1998), Ricky \& Stacy (2000), Anderson (1990), Woolfolk (1995), Hacker (1999), Carr \& Jessup (1997), Scott (2000), Seif (2000), Ebrahimi Ghavamabadi (1998), Ababafo(1996), Avansian (1998), and Barkhodarpour \&Sarmad (2000) who believe that instructing metacognitive strategies affects the students' scores.It can be inferred from the findings of this hypothesis that instructing metacognitive strategies is effective in improving the students' reading comprehension ability and, consequently, their performance in science lessons. That's because such instructions help the students to organize and store the newly learnt information and combine them with old information, which leads to improvement in learning other lessons.

It was also revealed that cognitive and metacognitive strategies-compared to the usual methods of learning- increase the educational self esteem of the students. There was actually a significant difference between the mean score of educational self esteem of the students who used cognitive and meta- cognitive strategies and that of the control group. The findings of this hypothesis are consistent with those of Wilson (1999), Carr \& Jessup (1997) and Barkhodarpour \&Sarmad (2000) who believe that instructing cognitive and metacognitive strategies has a different effect on the students' self esteem.

The results of the study showed that cognitive and metacognitive strategies, compared to the usual methods of teaching, improve the students' overall educational performances. The findings of this hypothesis are in the same line with those of Brown \&Palinscar (1982), Ricky \& Stacy (2000), Anderson (1990), Woolfolk (1995), Hacker (1999), Carr \& Jessup (1997, Scott (2000), Seif (2000), Ebrahimi Ghavamabadi (1998), Ababaf (1996), Avansian (1998), and Barkhodarpour \& Sarmad (2000) who stated that instructing learning strategies is beneficial in improving the students' educational performance.

It can be inferred from the findings of this hypothesis that instructing such strategies will lead the learners to learn with a high self esteem. The students who benefit from such strategies are hard working, persevering, and responsible students. Therefore, it seems rather sensible that teaching such strategies to the students enhances their overall educational performance. Educational self esteem is influenced by educational experiences. Thus, the students' educational self esteem can be enhanced by improving the quality of education and increasing the students' successful experiences. This will facilitate their educational advancement. Fulfilling such a goal necessitates instructing cognitive and metacognitive strategies.

Based on the results of this study, teachers and those involved in the students' education can take measures in enhancing the students' educational self esteem by improving the quality of education, using learning methods skillfully, avoiding comparing the students to each other, and avoiding giving negative feedbacks to the students.

One of the most important skills for the students is their knowledge and self control which make them able to effectively cooperate with others in difficult situations. Instructing cognitive and metacognitive strategies paves the way to reach this goal.

There is a close relationship between learning and teaching methods, and a more positive correlation between these two and performance of the students. Therefore, teachers must do their best to adjust their teaching method with that 
of the students' learning. In this respect, instructing meta- cognitive strategies, particularly self organizing in learning, teaching, self starting, self controlling, and self judgment will lead to improvement in the quality of education. Reaching this very important goal necessitates instructing metacognition to the teachers first. The teacher must pave the way for the students' thought and creativity and by creating questions, active teaching methods, and using cognitive and metacognitive strategies improve the problem solving process in the students.

\section{Pedagogical Implications}

Based on the results of this study, the following points are recommended:

1. Training on meta-cognitive strategies especially self organization in learning, self starting, self observation, and self judgment will increase the quality of training. So, training on meta-cognitive strategies seems to be necessary and it is suggested that the teachers teach through these strategies.

2. Teachers should provide the students with opportunities for thinking and being dynamic and encourage the problem solving process in the students through the use of problem solving method, active teaching methods and application of cognitive and meta-cognitive strategies.

\section{Limitations of the Study}

There were some limitations in this study such as small sample size which restricts the generalizability of these results. Our study was conducted on only 87 students. Further studies are recommended with a large number of students from different cultural backgrounds to find out if the same strategies lead to success in their educational performance and if the students in other contexts and at different levels use different strategies.

\section{References}

Anderson, J. R. (1990). Cognitive Psychology and its Implications. NY: Freeman.

Avansian, E. (1998). Role of meta-cognitive approach on comprehension and learning speed of Tehran's guidance school girls. Master degree thesis, College of Psychology and Education. Tehran, Iran.

Barkhordarpour, Z., \& Sarmad, Z. (2000). The evolutionary relationship between triple capabilities and educational performance of normal and perspicacious students in the second grade. Journal of Psychology, 4(13), 64-82

Borkowski, J. G., \& Muthagrishna, N. (1992). Moving metacognition into classroom: Working Models and Effective Strategy Teaching, Promoting Academic Competence and Literacy in School. San Diego, CA: Academic publications.

Brown, A. L., \& Palinscar, A. S. (1982). Inducing strategic learning for test anxiety by means of informal self control learning. Topics in Learning and Learning Disabilities, 2(1), 1-16

Brown, A. L., \& Day, J. D. (1983). Macro-rules for summarizing texts: The development of expertise. Journal of Verbal Learning and Verbal Behavior, 22, 1-14

Carr, M., \& Jessup, D. (1997). Gender differences in first grade mathematics strategy use: social and metacognitive influences. Journal of Educational Psychology, 89(2), 318-328

Delavar, A. (1993). Research methodology in psychology and education. Tehran: Virayesh Publications.

Ebrahimi Ghavamabadi, S. (1998). How can we improve the students' apprehension level? Journal of Education, 5, 6-8

Ehrman, M. E., \& Oxford, R. L. (1990). Adult language learning styles and strategies in an intensive training setting. Modern Language journal, 74, 311-327. http://dx.doi.org/10.1111/j.1540-4781.1990.tb01069.x

Flavel, J. H. (1981). Cognitive monitoring. In W. P. Dickson (Ed.), Children's Oral Communication Skills. New York: Academic Press. pp. 35-60

Gardener, R. (1990). When children and adults do not use learning strategy: Toward a theory of settings. Review of Educational Research, 60, 517-530

Hacker, D. J. (1999). Metacognition: definitions and empirical foundations. Behavior Therapy, 34, 171-186

Lefrancois, G. R. (1994). Psychology for teaching. California: Wadsworth publications.

Marzban, A. (2006). The interdependence between the process and product of reading in English and Persian. Paper presented at LSP International conference, Johor, Malaysia.

Nolan, A., \& Morgan, B. (2000). The role of metacognition in learning. Journal of Educational Psychology, 50, 49-79 
O'Malley, J. M., \& Chamot, A, U. (1990). Language strategies in second Language acquisition. Cambridge: Cambridge University Press.

Oxford, R., \& Crookall. D. (1989). Research on language learning strategies, methods, findings, and instructional issues. Modern Language Journal, 73(4), 404-419. http://dx.doi.org/10.1111/j.1540-4781.1989.tb05321.x

Oxford, R. L., \& Niokos, M. (1989). Variables affecting choice of language learning strategies by university students. Modern Language Journal, 73, 291-300. http://dx.doi.org/10.1111/j.1540-4781.1989.tb06367.x

Phakiti, A. (2003). A close look at the relationship of cognitive and metacognitive strategy use to EFL reading achievement test performance. Language Testing Journal, 20(1), 26-56. http://dx.doi.org/10.1191/02655322031t243oa

Prokop, M. (1989). Learning strategies for second language users. London: The Edwin Mellen Press.

Richards, J. C., Platt, J., \& Platt, H. (1992). Dictionary of language teaching and applied linguistics. Singapore: Longman Singapore Publishers.

Ricky, D., Stacy, \& A. M. (2000). The role of metacognition in learning chemistry. Dept of chemistry, University of California, 77(7), 915

Salataci, R., \& Akyel, A. (2002). Possible effect of strategy instruction on L1 and L2 reading. Reading in a Foreign Language, 14, 1-17

Scott, J. (2000). Teaching the new science syllabus. Curriculum Support Teaching in Science, 7-12, 12(3), 1-3

Seif, A. (2000). Studying and learning methods ( $3^{\text {rd }}$ edition). Tehran: Ravan Publication.

Shokrpour, N., \& Fotovatian, S. (2006). Reading comprehension strategies as applied by Iranian EFL students. Indian Journal of Applied Linguistics, 32(1-2), 117-132

Shokrpour, N., Zarei, E., Zahedi, S., \& Rafatbakhsh, M. (2011). The impact of cognitive and metacognitive strategies on test anxiety and students' educational performance. European Journal of Social Sciences (EJSS), 21(1), $177-189$

Schoomer, M. (1993). Epistemological development and academic performance among secondary students. Journal of Educational Psychology, 85, 306-311

Weinstein, C. E., \& Hium, L. M. (1998). Study strategies for lifelong learning. Washington D. C.: Americal Psychological Association. http://dx.doi.org/10.1037/10296-000

Wilson, J. (1999). Defining metacognition: a step towards rrecognizing metacognition as a worthwhile part of the curriculum. Washington D.C.: American psychological association.

Woolfolk, A. E. (1995). Educational psychology. Boston: Allyn \& Bacon.

Yin, W. M., \& Agnes, Ch. Sh. (2001). Knowledge and Use of Metacognitive Strategies. National Institute of Education Singapore. [Online] Available: http://www.aare.edu.au/01pap/won01419.html

Table 1. The students' total mean scores in self esteem and educational performance in both pre- and post-tests.

\begin{tabular}{|c|c|c|c|c|}
\hline \multirow{2}{*}{ Variables } & \multicolumn{2}{|l|}{$\begin{array}{l}\text { Educationalself } \\
\text { esteem }\end{array}$} & \multicolumn{2}{c|}{$\begin{array}{c}\text { Educational } \\
\text { performance }\end{array}$} \\
\cline { 2 - 5 } & Pre-test & Post-test & Pre-test & Post-test \\
\hline Total score & 88 & 85 & 20 & 20 \\
\hline Mean score & 52.85 & 54.01 & 14.31 & 18.74 \\
\hline $\begin{array}{c}\text { Standard } \\
\text { deviation }\end{array}$ & 6.55 & 7.65 & 4.96 & 14.07 \\
\hline Minimum grade & 30 & 22 & 177 & 191 \\
\hline Maximum grade & 68 & 70 & 340 & 675 \\
\hline
\end{tabular}


Table 2. Comparison of self esteem mean scores in pre- and post-tests. (cognitive group)

\begin{tabular}{|l|l|l|l|l|l|}
\hline variable & Mean & SD & df & T- test & P value \\
\hline Self esteem & 50.81 & 5.56 & 28 & 67.68 & 0.001 \\
\hline
\end{tabular}

Table 3. Comparison of the educational performance mean scores in pre- and post-tests (cognitive group)

\begin{tabular}{|c|c|c|c|c|c|}
\hline Variables & $\begin{array}{c}\text { Mean } \\
\text { score }\end{array}$ & $\begin{array}{c}\text { Standard } \\
\text { Deviation }\end{array}$ & $\begin{array}{c}\text { Freedom } \\
\text { Degree }\end{array}$ & $\begin{array}{c}\text { The } \\
\text { computed } \\
\mathrm{t}\end{array}$ & $\begin{array}{c}\text { Significance } \\
\text { Level }\end{array}$ \\
\hline $\begin{array}{c}\text { Educational } \\
\text { Performance }\end{array}$ & 286.44 & 40.63 & 28 & 47.81 & 0.001 \\
\hline
\end{tabular}

Table 4. Comparison of self esteem scores in pre- and post-tests (metacognitive group)

\begin{tabular}{|l|l|l|l|l|l|}
\hline variable & Mean & SD & df & T- test & P value \\
\hline Self esteem & 50.93 & 7.21 & 29 & 54.71 & 0.001 \\
\hline
\end{tabular}

Table 5. Comparison of the educational performance scores in pre- and post-tests (meta-cognitive group)

\begin{tabular}{|l|l|l|l|l|l|}
\hline variable & Mean & SD & df & T- test & P value \\
\hline $\begin{array}{l}\text { Educational } \\
\text { performance }\end{array}$ & 27.67 & 4.76 & 29 & 44.22 & 0.001 \\
\hline
\end{tabular}

Table 6. Comparison of the natural sciences' scores in pre- and post-tests in the meta-cognitive group

\begin{tabular}{|l|l|l|l|l|l|}
\hline variable & Mean & SD & df & T- test & P value \\
\hline $\begin{array}{l}\text { Natural } \\
\text { Sciences } \\
\text { Course } \\
\text { (total=20) }\end{array}$ & 15.25 & 4.12 & 29 & 25.63 & 0.001 \\
\hline
\end{tabular}

Table 7. Comparison of the students' self esteem mean scores in the cognitive, metacognitive and control group

\begin{tabular}{|l|l|l|l|l|l|}
\hline Variable source & Sum of squares & df & $\begin{array}{l}\text { Mean of sum of } \\
\text { squares }\end{array}$ & F & P value \\
\hline $\begin{array}{l}\text { Inter group } \\
\text { Intra group } \\
\text { total }\end{array}$ & 1046.8 & 2 & 523.4 & 9.39 & 0.032 \\
\hline
\end{tabular}


Table 8. Comparison of self esteem mean scores in the cognitive, metacognitive and control groups, using Sheffe test

\begin{tabular}{|l|l|l|l|l|}
\hline \multicolumn{1}{|c|}{$\begin{array}{c}\text { Mean } \\
\text { differences }\end{array}$} & \multicolumn{1}{|c|}{ Group } & (1) & (2) & (3) \\
\hline 1.12 & Cognitive(1) & & & $\times$ \\
0.28 & Metacognitive(2) & & & $\times$ \\
7.11 & Control(3) & & & \\
\hline
\end{tabular}

Table 9. Comparison of the students' total educational performance mean scores among the cognitive, metacognitive, and control groups.

\begin{tabular}{|c|c|c|c|c|c|}
\hline $\begin{array}{c}\text { Variable's } \\
\text { source }\end{array}$ & Squares & $\begin{array}{c}\text { Freedom } \\
\text { Degree }\end{array}$ & $\begin{array}{c}\text { Mean } \\
\text { Scores } \\
\text { of } \\
\text { Squares }\end{array}$ & F & $\begin{array}{c}\text { Significant } \\
\text { Level }\end{array}$ \\
\cline { 1 - 4 } Inter groups & 1369130.6 & 2 & 0.3 & \multirow{2}{*}{219.83} & \multirow{2}{*}{0.001} \\
\cline { 1 - 4 } Intra groups & 230444.89 & 74 & 0.68457 & \\
\hline Total & 1599575.5 & 76 & 3114 & & \\
\hline
\end{tabular}

Table 10. Comparison of student's mean score differences in their educational performance in the cognitive and meta-cognitive and control groups, using Scheffe method.

\begin{tabular}{|c|c|c|c|}
\hline Groups & $\begin{array}{c}\text { Mean score's } \\
\text { differences }\end{array}$ & 2 & 3 \\
\hline Cognitive & 289.04 & & $\times$ \\
Meta-cognitive & 279.09 & & $\times$ \\
Control & 9.95 & & \\
\hline
\end{tabular}

